\title{
UNEMPLOYMENT AND THE STRUCTURE OF LABOR DEMAND
}

\section{The Debate}

One of the most inconclusive debates in the history of American academic economics is the debate over the impact of structural shifts in the economy on employment conditions. Beginning in the late 1950's Charles Killingsworth and others argued that rising unemployment rates were in part due to structural shifts in the economy.l Eckstein, Heller, Knowles, Kalachek, and Gordon, among others, vociferously denied the importance of these structural shifts for the labor market and argued that lagging aggregate demand was the culprit. 2 The debate has been fought to a draw. Neither side has budged from its original position, and both sides claim definitive proof that their opponents are wrong. Some of the prominent "aggregate-demanders" have displayed a curious inability to understand what the structuralists were saying. The structuralists, on the other hand, have developed few specifically testable and "brittle" hypotheses, and have produced little hard research to support their position.

The structuralists argue that the unsatisfactory performance of labor markets in the late 1950's and early 1960's was due to structural problems with labor demand, i.e., persistent. imbalances of labor demand and supply for certain categories of workers. Proponents of this theory cite the "twist" in the demand for labor due to automation and the relative decline of goods-producing industries as the source of structural unemployment and "hidden" unemployment, i.e., abnormally low participation rates due to discouragement. 3 Killingsworth has recentIy added to the list of structural changes within the economy as follows: 4

1. Favorable employment conditions during the 1940's drew many poor blacks and whites from rural areas into large cities at the same time that agricultural technology was pushing these people off the farm. After 1953, the armed services demobilized, thus dumping more men on the labor market.

2. As defense purchasing dropped, it also changed in

*The author is a graduate student at the University of Michigan, and beginning in September 1969, will be an Assistant Professor of Economics at American University in Washington, D.C. The data used in this paper was generated by research supported by a grant from the Manpower Administration, U.S. Dept. of Labor. 
composition. Military demand shifted away from wheeled vehicles, munitions, and aircraft to sophisticated electronic gear, missles, and space craft. At the same time, cost-plus defense contracts became less important. This shift in military demand was unfavorable to low skilled, poorly educated workers and created shortages of engineers and technicians.

3. The geographical locus of industrial activity was shifting and decentralizing, moving away from the central city where the poor tend to live, to the suburbs and semirural areas, and to the South and west.

Except for the importance of automation, these changes in the structure of the economy were not at issue in the debate. The disagreement was whether these changes were taking place at an accelerating pace and whether these changes had any appreciable effect on the labor market which resulted in higher than expected unemployment and lower than expected labor force participation.

Some of the criticism of the structuralist approach has been aimed at only untenably extreme forms of the hypothesis. Knowles and Kalachek and Simler, among others, for example, began their research by assuming that the structuralists denied that sagging aggregate demand had any effect on labor markets even though the most prominent structuralist. Killingsworth. has said explicitly and repeatedly that structural shifts were only part of the problem. 5 Much of the empirical analysis attempting to disprove the structuralist hypothesis has merely analyzed the industrial and occupational composition of the unemployed even though there are serious difficulties with this approach. Lipsey, Gruber and Cohen, and Gilpatrick have ably discussed shortcomings of the criticism of the structuralists, and we shall not review this criticism in detail. $6,7,8$

Whereas there have been no conclusive attacks on the structuralist approach, there has also been little hard research supporting the strugcturalists. In 1964, Lipsey proposed a test of the hypothesis.9 The government should act, he said, to increase aggregate demand with fiscal and monetary policies until the point of unacceptable inflation is reached. If the level of unemployment is still unacceptable, then we should conclude that there are structural problems. Killingsworth has examined this approach in the light of evidence from the period up to 1967 and found support for the structuralist hypothesis. If Even though the unemployment rate was moderately low in 1967, though still well above the 2.98 rate achieved in 1953, considerable inflation resulted at the same time that several structural programs were in effect. These structural 
rograms included the military draft, several manpower training orograms from the Johnson administration's "War on Poverty," the investment tax credit, excise tax cuts, war procurement inzreases, and changes in social security regulations which allowad earlier retirement. Some of these programs, of course, are lemand programs, but they did not increase aggregate demand ivenly in all sectors of the economy; instead, they benefited those sectors which were allegedly the sources of structural inemployment.

Others have tried to examine the structuralist hypothesis using a variety of tests. Gruber has shown that poorly educated men when compared with better educated men fared worse in the labor market in 1960 then in 1950 (even though demand conlitions were approximately the same in the two years) as measured by unemployment rates and participation rates.ll Bergmann and Kaun found that only teenagers and blacks are having inireased structural difficulty as measured by elasticities of jroup unemployment rates to total unemployment rates.12 Giljatrick has made the most exhaustive examination of the structuralist hypothesis, using data from a number of sources and naking a number of different tests.13 She found that older men, pouth who were new entrants to the labor force, blacks, the joorly educated, and the low skilled were increasingly subject to structural problems.

Although the structuralist-aggregate demand debate has seen carried on entirely within a time series frame of reference, it is possible to generalize the structuralist hypothesis to a cross section (intercity) approach. Accordingly, we might aypothesize that cities with industrial and occupational structures which offer relatively prevalent job opportunities for Low skilled or poorly educated workers will cet. par. have lower nemployment rates (or at least lower rates for low skilled vorkers) than cities which do not. Since the poor are overwhelmingly poorly educated and low skilled, the same statement zould be made concerning the poor. Somewhat more tentatively, ve predict that poor nonwhites are more sensitive to structural lifficulties than poor whites for there is some evidence that a greater proportion of urban poor nonwhites are found in low skilled occupations than urban poor whites. Data from the urrent Population Survey indicate that less than half of vhites living in urban poverty tracts are operatives, laborers, or service workers, whereas more than three quarters of non-
vhites in poverty tracts are in those occupations. 14

One can test the hypothesis that variations in the structure of labor demand (in addition to variations in the level of labor demand) will affect unemployment rates in a cross section. 15 The results will be interesting in themselves, but ve should also like to know if the cross section test is in any 
way a test of the time series hypothesis as suggested by Killingsworth and others. There are several reasons why the structural hypothesis may operate differently in a time series and a cross section:

1. If structural problems are incurred evenly throughout the economy, then a cross section analysis could not detect them, since a cross section analysis can only measure differences between cities.

2. Even if structural difficulties are distributed unevenly, migration may tend to smooth out the incidence of structural unemployment, Nevertheless, if either 1 or 2 are correct, this would deny one of the proposed sources of structural problems, i.e., geographically uneven economic growth.

3. The cross section test of the structuralist hypothesis is likely to measure a long term response to persistent structural forms, rather than the short term response of which Killingsworth writes.

4. Even if none of the above are relevant or important, we must be cautious in generalizing from a cross section to a time series. Changes between cities are just not the same as changes over time even if one cannot specify exactly why. The cross section test can thus only be a tentative test of the time series hypothesis.16

\section{A Cross Section Test of the Structuralist Hypothesis}

The structure of labor demand is not an easy variable to operationalize and, unfortunately, few precedents exist. Bowen and Finegan constructed an index of the demand for female workers, and several of the structural measures used here are patterned after the Bowen and Finegan index. 17 First, they computed the proportion of females in each of thirty-five two- and three-digit industries (which represent an exhaustive categorization of all workers). For example, 28.38 of all workers in public administration in the U.S. in 1960 were women. Assuming that the public administration industry in Baltimore, for example, is merely a small scale version of the entire industry, we would expect that 28.38 of the 44,805 , or 12,680 workers in public administration in Baltimore would be women. In fact, we find that there were 14,418 females in public administration in Baltimore, but it is assumed that this is not due to Baltimore's public administration industry differing from the national industry (in any respect but scale) but is due to other factors such as a relatively more abundant supply of women in Baltimore. Adding the expected number of female workers in each industry 
together, we can estimate the total number of females that we would expect to find working in Baltimore. This sum is divided by the total number of workers and the resulting fraction measures the relative demand for female labor in Baltimore. The calculations are then iterated for every city to be examined. More formally, we might describe these calculations as:

$$
\frac{\sum_{i=1}^{N} r_{i} E_{i c}}{\sum_{i=1}^{N} E_{i c}} \quad \text { for every } c
$$

where $\underline{r}_{i}$ is the proportion of females in industry $\underline{i}$, and where $E_{i c}$ is the number of employees in industry $\underline{i}$ in sMMSA $c$.

In the following research, the technique developed by Bowen and Finegan to measure the demand for female workers was adapted to measuring the demand for skilled or well educated workers. More specifically, the Bowen and Finegan formula was used, but instead of setting $\underline{r}_{j}$ equal to the proportion of females in industry $\underline{\underline{i}}, \underline{\underline{r}}_{i}$ was sudcessively set equal to:

1. the proportion of workers in industry $i \underline{i}$ who, in the estimation of personnel managers in the industry, require a high school degree to attain average proficiency in their job;

2. the proportion of workers in industry $i$ who, in the estimation of personnel managers in the industry, require six months or more of vocational training specific to their job to attain average proficiency; and

3. the proportion of workers in urban areas in industry i. who were nonwhite. 18

In this manner, we compute indices ostensibly measuring the demand for educated workers, the demand for skilled workers, and the demand for black workers.

All of these indices assume a balkanization of labor markets, a labor market with low cross elasticities of demand for different categories of workers. This assumption is most questionable in the case of the index of demand for black workers. This index is a valid measure only if certain jobs are more or less rigidly (between cities) categorized as "black" jobs. It would be expected that since blacks are typically less skilled and more poorly educated than whites, blacks would be concentrated in jobs requiring little education and few skills. But 
if the index of demand for blacks is to be a valid measure, it must be something more than an index of demand for the low skilled. In fact, the measures are intercorrelated, but the correlation between the index of demand for nonwhites and other structural indices is sufficiently low so that we can tentatively conclude that these are independent measures. The simple correlation coefficient (R) for poor blacks between the nonwhite index and the other structural indices are as follows: the education index, +.525; the skill index, +.397; and the occupational index, -.336 (see below).

A second type of structural variable measuring the skill mix of labor demand is the proportion of the labor force who were operatives, laborers, or nonhousehold service workers, hereafter termed the occupational index.

The effects of economic environment on unemployment is examined in a selection of twenty-nine very large SMSA's which were chosen to represent a broad geographical coverage of the United states. Census data by tract for 1960 are used in this analysis. A random sample of tracts was selected from the twenty-nine SMSA's. The sampling was stratified by SMSA and by average income level in the tract. The sampling fraction for tracts in the lowest quartile of family and unrelated individual's income in the SMSA was 308 , whereas the sampling fraction in the higher quartiles was 108 . Thus, equal numbers of poor and nonpoor tracts were selected, yielding a global sampling fraction of 158. Data are published by the Census for the total population of each tract, and separately for nonwhites, if 400 or more lived in the tract. By subtracting data for nonwhites from the data for the total, we can estimate data for whites.

The most important predictor of the average employment rate (one minus the unemployment rate) within a tract should be the employment rate for the entire SMSA in which the tract lies. Other important predictors should be the average levels of educational attainment, age, school enrollment, and marital status of the population of the tract. Education is measured by the proportion of the population of the tract 14 and over with a high school degree. Age is measured by the proportion of the male or female population of the tract 14 and over who are between 25 and 54. Marital status is measured by the proportion of males or females 14 and over who live with their spouse. School enrollment is measured by the proportion of the population 14 and over who are enrolled in high school or college. For the purposes of this research, we are not primarily interested in the effects of these variables on employment, but the analysis must control for these factors.

Tracts with 158 or more of its population living in group 
quarters (e.g., dormitories, prisons, hospitals) were omitted from the analysis and the proportion of the population in group quarters (from zero to 14.98) was included in each regression as an added control. Furthermore, in regressions for nonwhites, tracts where 858 or less of the nonwhite population was black were omitted from the analysis, so that the data for nonwhites are essentially data for blacks. The statistical technique used in analyzing the tract data was linear multivariate single stage least-squares regression analysis. In the regressions, the data were weighted by the population of the tract and the inverse of the sampling fraction.

\section{The Results}

The employment rate for males in census tracts was regressed on the SMSA employment rate, education, age, marital status, school enrollment, and the group population variables. (Employment rate for females by tract was not available). Afterwards, variables describing the structure of the labor market were added to the list of independent variables. For the purposes of presentation, only the regression coefficients on the employment rate and the structural variables are presented.

The first row of coefficients in Table I represent the regression coefficients and their standard errors on the SMSA employment rate for the regressions in which the only independent variable besides the non-economic variables was the SMSA employment rate. Other rows in the table show the regression coefficients of both the employment rate and the structural variables as they were added to the basic regressions one at a time. As expected, black males are more sensitive to overall demand conditions than whites. Also poor whites are more sensitive to the SMSA employment rate than nonpoor whites. Surprisingly, nonpoor black males are more sensitive to the SMSA employment rate than poor black males. We should be cautious, however, in accepting this last statement since there are very. few observations (93) for nonpoor blacks. There is some annoying multicolinearity between the employment rate and the structural variables. Therefore, the coefficients on employment jump around as different structural variables are added. Nevertheless, there is not enough variation in the employment rate coefficients to induce us to change any of the above conclusions.

It was expected that the structural variables would be more important for the poor than the nonpoor and more important for the poor black than the poor white. None of these expectations, however, are supported by the regression results in Table I. The coefficients on the indices of demand for educated 


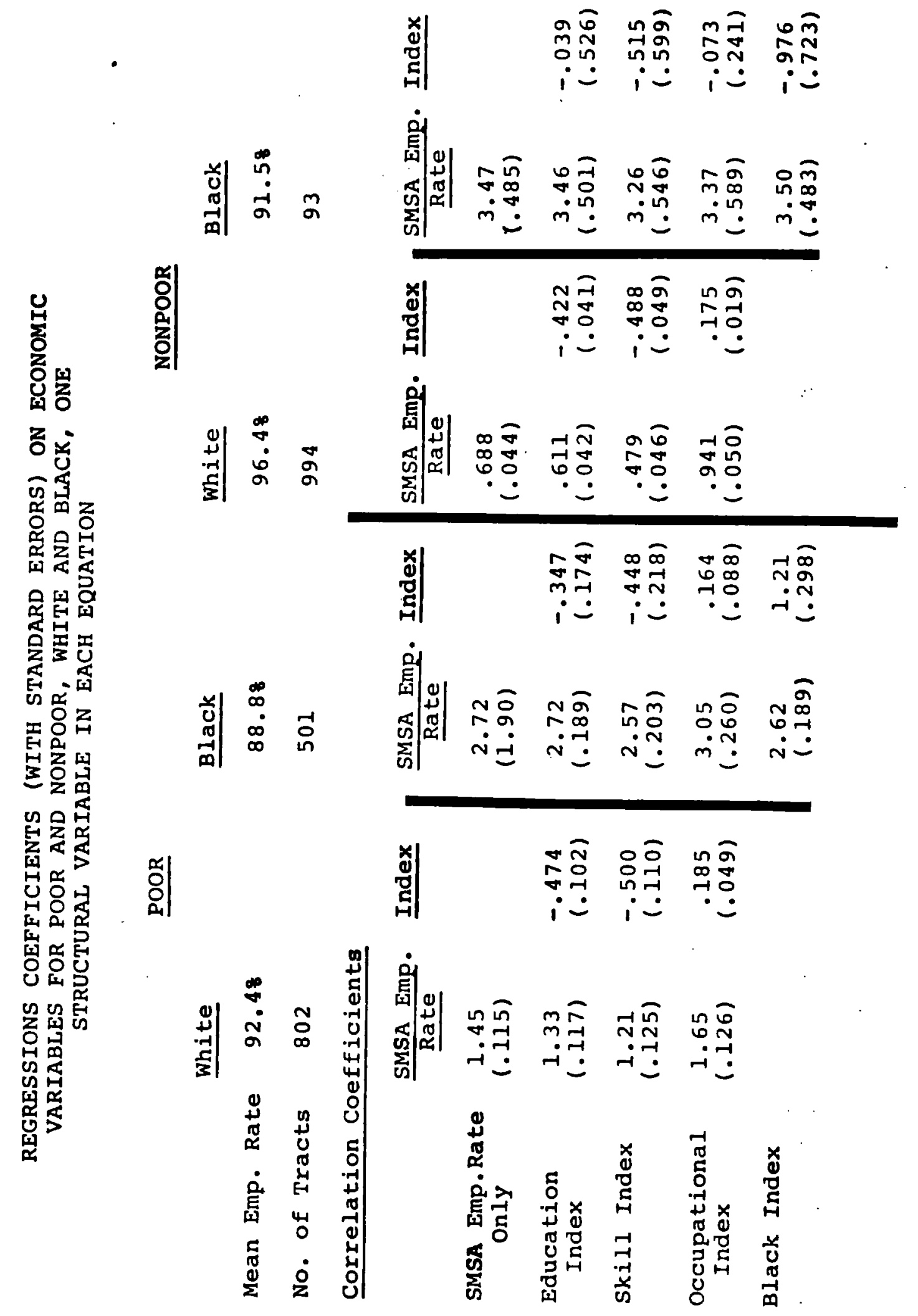


workers and skilled workers have the expected negative sign for all groups, but the size of the coefficients do not vary appreciably from one group to another. (except for the nonpoor black males where the coefficients are insignificant at the .05 level). The coefficients on the occupational index are positive as expected and also about the same size for all groups (except for nonpoor black males). For the poor whites, the poor blacks, and the nonpoor whites, all of the coefficients on the three structural indices are significant at the 0.05 level except the occupation index for poor blacks $(t=1.86)$. Six of the nine coefficients are significant at the 0.01 level. The range of these structural variables are such that the employment rate could vary as much as 2 or 3 percentage points between the labor market with the highest skill requirements and the labor market with the lowest.

The only structural factor which discriminates between poor whites, poor blacks, and nonpoor whites is the index of demand for nonwhite workers. This index is positive and highly significant for poor black males but is negative and insignificant for nonpoor black males. The index was negatively associated with employment rates of poor whites $(t=2.33)$.

One remaining question is the additivity of these structural measures. Do they each exert an independent effect on employment in a cumulative fashion or are they to some extent measuring the same thing so that their combined effect is no larger than any of the separate effects? The multicollinearity between the index of demand for educated workers and the other structural indices is so great that our question is answered without further investigation--they cannot be measuring very different things. Nevertheless, the simple correlation between the skill index and the occupational index is sufficiently low that there are no statistical obstacles to including them both in the same regressions.

Table II presents the regression coefficients on employment, the skill index, and the occupational index for each group. It can be seen that the inclusion of more than one structural variable in the equation does not appreciably affect the size of the coefficient on the employment rate. Nevertheless, for poor whites, poor blacks, and nonpoor whites, the coefficients on both the skill index and the occupational index becomes smaller when they are both included in the same equation. Both coefficients on the structural variables for the poor blacks and one of the coefficients for the poor whites drop to insignificance. The coefficients for the nonpoor blacks remain insignificant and with inconsistent signs. From these statistics, one should tentatively conclude that the various structural indices are not additive but to a large extent are measuring the same phenomenon. 
REGRESSION COEFFICIENTS (WITH STANDARD ERRORS) ON ECONOMIC VARIABLES FOR POOR AND NONPOOR, WHITE AND BLACK, MORE THAN ONE STRUCTURAL VARIABLE FOR EACH EQUATION

SMSA Employment Rate
Skill Index
Occupational Index

$\underline{\text { Poor }}$

Whites

Blacks

(.153)

$-.391$

(.225)

$-3.23$

(.260)

$$
\begin{aligned}
& .102 \\
& (.056)
\end{aligned}
$$

.093

(.105)

Nonpoor

Whites

$$
\begin{aligned}
& .670 \\
& (.061)
\end{aligned}
$$

$-.359$

$(.054)$

.112

(.021)

Blacks

$$
\begin{gathered}
2.79 \\
(.765)
\end{gathered}
$$

$-.830$

$(.700)$

$-.245$

(.281) 
If the index of demand for blacks is added to the above equations for blacks, however, somewhat different conclusions emerge. As shown in Table III, none of the coefficients for the nonpoor blacks are significant, but now all of the coefficients on the economic variables are significant at the .05 level for poor blacks. Furthermore, the coefficients on the structural varibles are now fifty to one hundred percent larger than they were when only one structural varible was included in each regression. (Adding the index of demand for blacks to the equations for whites does not affect the coefficients on other variables). Poor blacks, therefore, in a local labor market with relatively low demand for black workers, a low demand for unskilled workers, and a low demand for operatives, laborers, and service workers, will tend to have higher unemployment rates even after controlling for a number of other economic and demographic factors. In fact, poor blacks in SMSA's where all of the structural factors work to their detriment, could conceivably have unemployment rates fifteen percentage points higher than under the most favorable conditions. This is in addition to the already considerable impact that the level of local labor demand has upon the unemployment of poor blacks.

These findings suggest two considerations: First, the structural factors may be cumulative for poor blacks but not others. Second, since the skill and occupational indices became significant only after the index was added, controliing for the demand for blacks may be necessary before one can determine the true impact of the other structural variables on the employment rates of poor blacks.

Accordingly, the regressions shown in Table I were reestimated for blacks with the black index included. Table IV presents the statistics from these new equations. None of the structural variables are significant for the nonpoor blacks; but for poor blacks, all of the structural variables taken in succession are significant at the .01 level and are more than double the size of the coefficients when the black index was not included in the regressions. Apparently, if one can properly control for the demand for blacks, the other structural factors are about twice as important for poor blacks as for whites, and thus the predictions from the structuralist hypothesis are in part supported. This conclusion does not seem to be a statistical mirage due to multicoliinearity between the black index and other structural indices. As noted above, multi. collinearity between the black index and othor structural variables is tolerably low. 
REGRESSION COEFFICIENTS (WITH STANDARD ERRORS) ON ECONOMIC VARIABLES FOR POOR AND NONPOOR BLACKS, MORE THAN ONE STRUCTURAL VARIABLE WITH BLACK INDEX

$\frac{\text { SMSA Employment }}{\underline{\text { Rate }}} \quad \frac{\text { Skill }}{\underline{\text { Index }}} \quad \frac{\text { Occupational }}{\underline{\text { Index }}} \quad \frac{\text { Black }}{\text { Index }}$

BLACKS

$\underline{\text { POOR }}$

$$
\begin{gathered}
2.73 \\
(.318)
\end{gathered}
$$$$
-.905
$$$$
.253
$$$$
(.104)
$$

2.22

$(.344)$

NONPOOR

$$
\begin{gathered}
2.94 \\
(.777)
\end{gathered}
$$$$
-.577
$$$$
-.228
$$ 


\section{TABLE IV}

REGRESSION COEFFICIENTS (WITH STANDARD ERRORS) ON ECONOMIC VARIABLES FOR POOR AND NONPOOR BLACKS, ONE STRUCTURAL VARIABLE IN EACH REGRESSION WITH BLACK INDEX

$\frac{\text { SMSA Employment }}{\underline{\text { Rate }}} \quad \frac{\text { Structural }}{\underline{\text { Index }}} \quad \frac{\text { Black }}{\text { Index }}$

POOR

Education Index

Skill Index

Occupation Index
$-1.14$

$(.205)$

$$
-1.17
$$

(.243)

$(.209)$

3.37

(.259)

.399

(.099)

2.36

(.355)

2.02

(.335)

1.82

$(.327)$

NONPOOR

Education Index

Skill Index

Occupation Index

$$
\begin{gathered}
3.55 \\
(.502)
\end{gathered}
$$

3.38

$(.556)$

3.34

$(.586)$
.243

$(.560)$

$-.274$

(.636)

$-.117$

(.242)
$-1.10$

$(.778)$

$-.863$

(.773)

$-1.02$

(.733) 
The debate over the importance of structural shifts in the economy for employment conditions has raged for over a decade with neither side admitting to error. The present research augments the work of others who have found support for the structuralist position. More specifically, this research has found that structural factors are important determinants of the employment of black men. The novel conclusion of this research is that structural factors are as important for nonpoor white men as for poor white men though the effects of variation in structure on employment rates is much smaller for all whites than blacks. The finding that structural factors are important for whites, however, may be a result of the methodology used. The response of white male employment to structural factors in an intercity analysis may represent very long term adjustments, and thus could not be detected in time series analysis with ten or fifteen observations.

The methodology of the present research is perhaps of greater import than its findings. In the post-Keynesian rush to disaggregate, little attention has been paid to the structure of local economies. Nevertheless, the proportion of employment in heavy industry, for example, in my sample of twentynine very large cities varies from 31.58 in Detroit to 1.58 in washington, D.C. Even though such vast variations in the structure of the local economy must have important implications for local labor markets, income distribution, cyclical effects, and growth patterns, among other things, the literature is virtualiy devoid of mention of these considerations.19 The present research is seen by its author as a first halting step in the attempt to quantify the structure of the local economy so that its importance can be investigated.

\section{Footnotes}

$1_{\text {Killingsworth has written a number of articles concern- }}$ ing the structuralist position. Perhaps the best known one is "Automation, Jobs, and Manpower," Subcommittee on Employment and Manpower, Committee on Labor and Public Welfare, United State Senate, Exploring the Dimensions of the Manpower Revolution, Vol.I, 1964, p.194-219. See also Jobs and Income for Negroes, 1968 .

20tto Ekstein, "Aggregate Demand and the Current Unemployment Problem," in Arthur Ross, editor, Unemployment and the American Economy, 1964, p. 116-134; Walter Heller, "The Administration's Fiscal Policy," in Ibid. p. 93-115; Edward Kalachek, 

${ }^{13}$ Gilpatrick, ㅇp. cit.

${ }^{14}$ James R. Wetzel and Susan S. Holland, "Poverty Areas of our Major Cities," Monthly Labor Review, October 1966, p. 1108.

15 Note that we are not testing one part of the structuralist hypothesis that the rate of structural change accelerated in the post-war period.

16 A more elaborate discussion of this problem is found in: Edward Kuh, "The Validity of Cross-Sectionally Validated Behavior Equations in Time Series Applications," Econometrica, No. 27, 1959, p. 197-214.

17 William G. Bowen and T. Aldrich Finegan, "Labor Force Participation and Unemployment," in Arthur Ross, editor, Employment Policy and the Labor Market, 1965, p. 115-161.

${ }^{18}$ The data by industry estimating the proportion of workers who require a high school degree or six months of training is adapted from an adaptation from the victionary of Occupational Titles. See R.S. Ekhaus, "Economic Criteria for Education and Training," Review of Economics and Statistics, May 1964 p. 187-189.

${ }^{19}$ A happy exception to this rule is found in the manifold works of Wilbur Thompson. See his Preface to Urban Economics, 1965. 

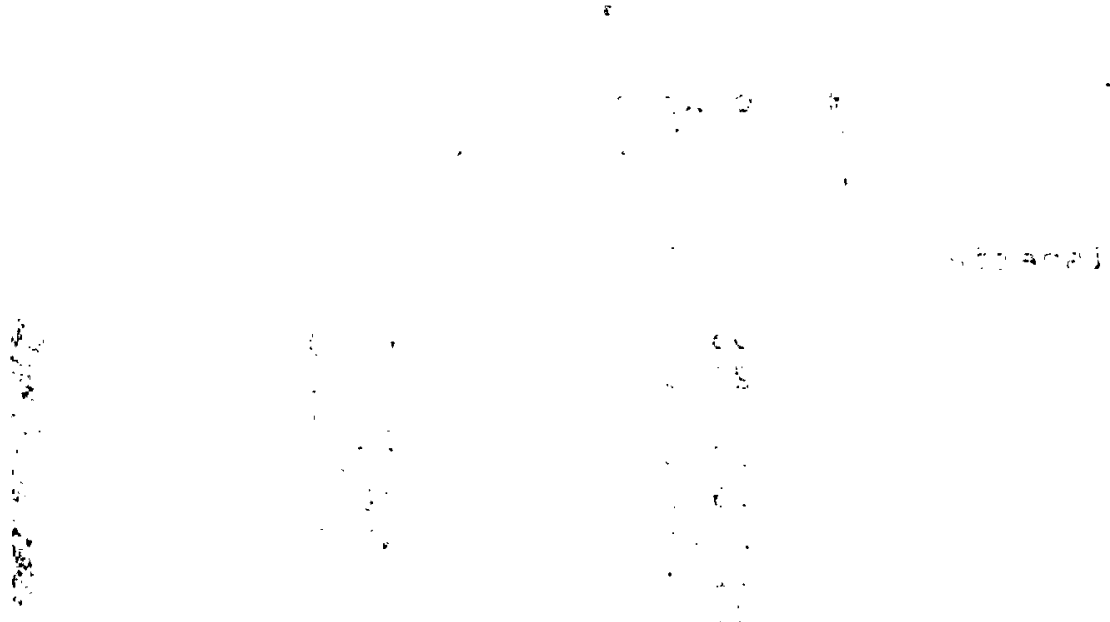

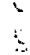

?.

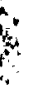

3

is

$\because$ 
TABLE II

STRUCTURAL MEASURES FOR 29 SMSA's USED IN ANALYSIS

SMSA

Atlanta

Baltimore

Birmingham

Boston

Buffalo

Chicago

Cincinati

Cleveland

Dallas

Denver

Detroit

Houston

Indianapolis

Kansas City

Los AngelesLong Beach

Memphis

Milwaukee

New Orleans

New York

Newark

Philadelphia

Phoenix

Pittsburgh

st. Louis

San Antonio

San Diego

San FranciscoOakland

Seattle

Washington, D. C. 39.8
Education Index

37.3

36.0

37.2

37.1

36.7

35.7

36.3

37.0

37.8

39.4

38.4

38.1

36.5

36.3

38.0

36.3

37.2

37.1

35.8

36.8

35.8

40.3

36.8

35.7

38.5

38.7

38.4

39.0

\section{Skill}

Index

44.2

42.6

45.0

43.3

43.8

42.4

42.9

44.0

44.6

45.7

45.2

45.3

43.1

42.7

44.5

42.9

44.1

43.8

42.2

43.9

42.5

46.5

44.6

42.3

43.9

44.4

44.7

45.4

43.7
Occupational

Index

29.2

32.7

34.8

29.4

35.2

31.7

31.8

33.7

27.9

26.7

35.4

29.6

31.5

29.8

29.1

33.2

34.7

33.0

30.8

30.7

33.5

25.9

35.6

33.3

30.7

26.5

27.1

27.0

20.3
Black

Index

10.6

9.8

11.5

8.5

9.3

8.3

8.9

8.9

9.7

9.6

9.1

9.6

8.9

9.1

8.9

il. 5

8.3

10.3

8.9

8.6

9.0

9.9

9.9

9.1

10.6

9.4

9.4

9.7

10.5 


\title{
APPENDIX B \\ ADEQUACY OF STRUCTURAL MEASURES OF THE BOWEN AND FINEGAN TYPE
}

\begin{abstract}
Thirty-five two- and three-digit industries were used in the computation of several of the structural indices used in the foregoing analysis. If more industries, $i . e .$, a finer breakdown of industries, had been used, the indices would have more accurately reflected the underlying industrial structure of each SMSA. This accuracy, however, would have been purchased at a greater cost.
\end{abstract}

The proportion of workers who require six months or more of vocationally specific training can be estimated for 96 industries, nearly three times as many as was actually used. After aggregating the 96 industries into 35 industries, 588 of the variance in the proportion of skilled workers for the 96 industries remained within the 35 categorizations, i.e., only 428 of the original variance was accounted for by the aggregated industries. There are no criteria for evaluating this information, but it would seem that there is a surprisingly large amount of variation within the aggregated categories.

Two caveats must be heeded. First, the disaggregated industries vary widely in size, from just over 20,000 to over 4,000,000 workers. The computations of unexplained variance would probably be reduced were the size of the industry taken into account. Second, variance between subindustries within an aggregated industry does not concern us if the mix of subindustries does not change between SMSA's. For example, the proportion of skilled workers in the public utilities industry varied between 168 (Sanitary services) to 608 (Electric light, and power, gas), but the composition of the utility industry is unlikely to vary between cities of the size analyzed in this research. On the other hand, the sizable variation within the transportation equipment industry ( 388 to 598 skilled workers) is more worrisome since the relative size of the motor vehicle, air craft, and ship building subindustries varies widely between cities. In other words, the transportation equipment industry in Detroit is motor vehicles, in Los Angeles, air craft, and in San Diego, ship building. Unfortunately, we have no way of evaluating the importance of this consideration. Thus the structural measures used in this research should be interpreted with caution. 